\title{
Identification of mouse Duffy Antigen Receptor for Chemokines (Darc) as a BMD QTL gene
}

\author{
Bouchra Edderkaoui, ${ }^{1}$ David J. Baylink, ${ }^{2}$ Wesley G. Beamer, ${ }^{3}$ Jon E. Wergedal, ${ }^{1,2}$ \\ Ryan Porte, ${ }^{1}$ Asok Chaudhuri, ${ }^{4}$ and Subburaman Mohan, ${ }^{1,2,5}$ \\ ${ }^{1}$ Musculoskeletal Disease Center, Jerry L. Pettis Memorial VA Medical Center, Loma Linda, California 92357, USA; ${ }^{2}$ Department \\ of Medicine and Biochemistry, Loma Linda University, Loma Linda, California 92354, USA; ${ }^{3}$ The Jackson Laboratory, Bar Harbor, \\ Maine 04609, USA; ${ }^{4}$ Laboratory of Cell Biology, New York Blood Center, New York, New York 10021, USA
}

\begin{abstract}
It is now well known that bone mineral density (BMD) variance is determined by both genetic and environmental factors. Accordingly, studies in human and animal models have revealed evidence for the presence of several quantitative trait loci (QTL) that contribute to BMD variations. However, the identification of BMD QTL genes remains a big challenge. In the current study, we focused our efforts to identify the BMD candidate gene in chromosome 1 (Chr 1) QTL that was detected from a cross involving high BMD CAST/Ei] (CAST) and low BMD C57BL/6] (B6) mice. To this end, we have combined several approaches including: (1) fine mapping the BMD QTL in Chr 1 of the B6.CAST $F_{2}$ female mice using a large number of polymorphic markers; (2) the generation of congenic sublines of mice by repeated backcrossing of CAST with B6 mice and phenotype characterization; (3) expression profiling genes in the QTL region; and (4) SNP analyses to identify the mouse Duffy Antigen Receptor for Chemokines (Darc) as a candidate gene for Chr 1 BMD QTL2. We verified the involvement of the Darc protein in BMD variation by evaluating the skeletal phenotype of Darc-knockout mice and congenic sublines of mice carrying small chromosomal segments from CAST BMD QTL. Based on the findings that Darc-antibody blocked formation of multinucleated osteoclasts in vitro and that Darc from CAST binds chemokines, known to regulate osteoclast formation, with reduced affinity compared with Darc from B6 mice, we conclude that Darc regulates BMD negatively by increasing osteoclast formation, and that the genetic association between Darc gene polymorphism and BMD variations in humans merits investigation.
\end{abstract}

[Supplemental material is available online at www.genome.org.]

Osteoporosis is a condition associated with decreased bone strength and an increased fracture risk. Its prevalence is increasing as more individuals with low bone mineral density (BMD), the strongest predictor of fracture risk, are detected. Thus, molecular dissection of the BMD regulatory system may reveal novel therapeutic targets for the treatment of osteoporosis. Several studies preformed on both humans and mice have shown that BMD has a strong heritable component, with estimates that genes account for $60 \%-80 \%$ of BMD variance (Morrison et al. 1994; Beamer et al. 1996; Devoto et al. 1998; Klein et al. 1998; Eisman 1999; Niu et al. 1999; Baldock and Eisman 2004). Accordingly, linkage studies in humans and experimental animal models have identified several BMD QTLs. However, the big challenge has been identifying the "QTL gene." To our knowledge, only a single QTL gene, Alox15, has been identified thus far as a BMD QTL gene (Klein et al. 2004).

To screen for BMD candidate genes, we have chosen to dissect the BMD QTL in chromosome 1, because this QTL has been identified in four different intercrosses: C57BL/6J (B6) $\times$ Cast/EiJ (CAST) (Beamer et al. 1999), B6 × C3H/HeJ (Beamer et al. 2001), B6 $\times$ DBA/2 (Klein et al. 1998), and MRL/MpJ $\times$ SJL/J (Masinde et al. 2002). Furthermore, a syntenic region in human chromosome 1q21-q43 carries a previously identified BMD QTL, which has been reported in independent studies using human popula-

${ }^{5}$ Corresponding author.

E-mail Subburaman.Mohan@va.gov; fax (909) 796-1680.

Article published online before print. Article and publication date are at http:// www.genome.org/cgi/doi/10.1101/gr.6009507. tions (Koller et al. 2000; Ralston 2002). In this report, we present data on the identification of Duffy Antigen Receptor for Chemokines (Darc) as a BMD QTL gene by utilizing a variety of molecular genetic approaches.

\section{Results}

Fine mapping and congenic sublines of mice

In a recently published study (Edderkaoui et al. 2006), we reported the identification of three BMD loci at Chr 1 by superimposing the CAST chromosomal regions carried by each congenic subline. The Bmd1a locus was located between D1mit133 and D1mit453 (133.2-165.2 Mb), the Bmd1b locus was located between D1mit113 and D1mit150 (171.86-174.76 Mb), and a Bmd1c, which regulates BMD negatively, was located between D1mit221 and D1mit511 (184.86-192.06 Mb). In this study, we further fine mapped the Chr 1 QTL region by genotyping 565 B6.CAST $\mathrm{F}_{2}$ female mice with a large number of polymorphic markers from this region. Interval mapping using MapQTL 4.0 to identify the linkage between polymorphic markers and femur total volumetric $\mathrm{BMD}$ (vBMD) within the $\mathrm{F}_{2}$ female mice showed three peaks/QTL: peak 1 at marker D1mit453 (Bmd1a, at 165.2 $\mathrm{Mb}$ ), peak 2 at marker D1mit354 (Bmd1b, at $172.98 \mathrm{Mb}$ ), and peak 3 at marker D1mit359 (designated as BMD1-4 at 177.4 Mb) (Fig. 1 ), which were significantly associated with femoral vBMD. MapMaker software also identified three significant linkages at the same positions (Supplemental Table 1), which explained 9.3\%, $10.7 \%$, and $9 \%$ of the BMD variation within the B6.CAST 


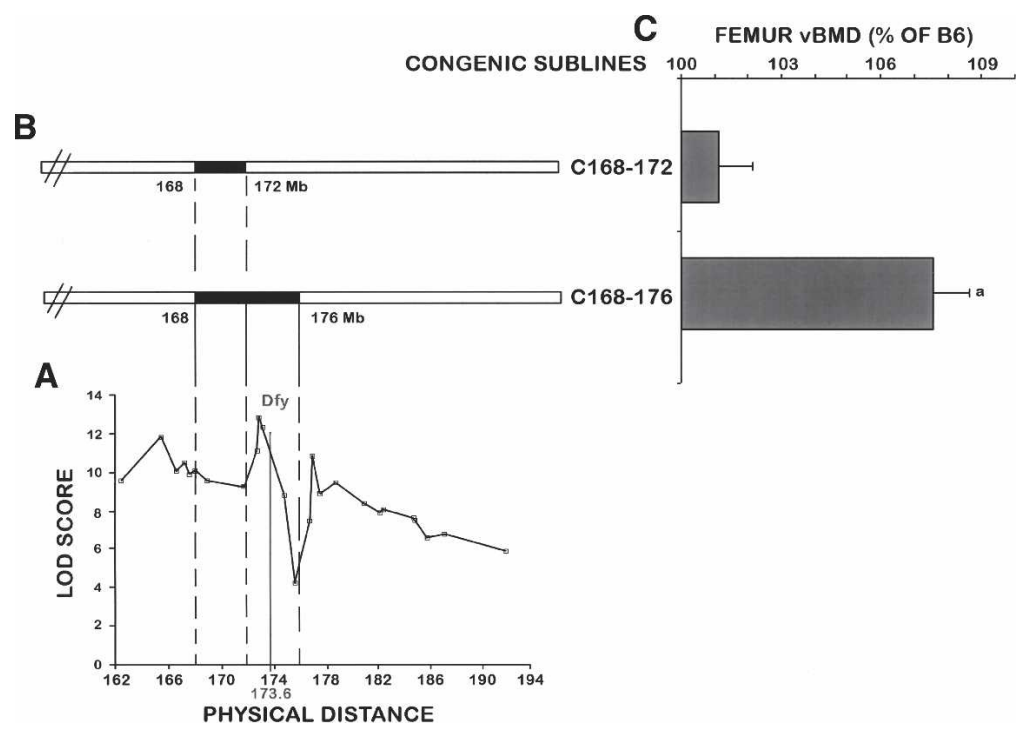

Figure 1. Genetic localization of the Darc gene and BMD phenotype of the two congenic sublines C168-172 and C168-176. (A) Fine mapping of BMD QTL in chromosome 1 using 33 polymorphic markers. Linkage analyses showed three peaks suggesting at least three BMD QTLs within Chr 1 . The $X$-axis represents the physical distance beginning with the centromeric side and extending toward the telomeric side of Chr 1, starting from marker D1 mit106 at $162.33 \mathrm{Mb}$ according to the National Center for Biotechnology Information database (http://www.ncbi.nlm.nih.gov/). The $Y$-axis represents the likelihood values for the presence of a segregating QTL at each marker (LOD score). Genetic localization of the Darc gene within the second BMD QTL $(B m d 1 b)$ is indicated. (B) Solid bars represent the CAST chromosomal regions carried by each congenic sublines. (C) Femoral vBMD at the mid-diaphysis of the two sublines C168-172 and C168-176 compared with B6 control mice. Each congenic subline is presented (C, referring to the cast allele), followed by the position (in megabases) of the two markers flanking the donated CAST segment. We designated the congenic subline B6.CAST-1 ${ }^{\text {D1 mit370-D1 mit403 as }}$ C168-176, which indicates the approximate proximal and distal megabase limits known for the CAST chromosomal region, and the congenic subline B6.CAST-1 ${ }^{D 1 m i t 370-D 1 m i t 113}$ was designated as C168172. Data are expressed as a percentage of $B 6$ and are mean \pm SEM. (a) $P<0.01$ as measured by Student's $t$-test in congenic subline vs. B6 mice. $n=10-14$.

$\mathrm{F}_{2}$ population, respectively. Thus, Chr 1 contains at least four BMD loci, three of which regulate BMD positively and one negatively.

Since the Bmd1b QTL showed the highest LOD score, we chose to screen BMD candidate genes within this locus. Therefore, to narrow down the size of the Bmd1b QTL region to permit our candidate gene search, we generated additional congenic sublines from the C168-185 subline, as described in Edderkaoui et al. (2006). In the present study, we compared the skeletal phenotype of the congenic subline that carries the CAST chromosomal segment from D1mit370 to D1mit403 (168-176 Mb) and the congenic subline that carried the CAST chromosomal region D1mit370-D1mit113 (168-172 Mb) located between the first and the second peaks/QTL with the B6 control mice (Fig. 1). The congenic subline C168-176 exhibited a significantly greater vBMD compared with the B6 mice $(7.5 \%, P=0.01)$, while C168172 did not show any differences compared with the B6 controls. Using this data, we could safely eliminate the genes located at the $168-172 \mathrm{Mb}$ chromosomal region from further analyses (Fig. 1), which narrowed down the size of the Bmd1b locus to 172-176 $\mathrm{Mb}$ from the centromere in Chr 1. Furthermore, the C168-176 subline exhibited a significantly smaller femur trabecular volume and reduced midshaft endosteal circumference, but no difference in the periosteal circumference (Fig. 2). These changes contributed to an increase in the cortical thickness and correspondingly higher vBMD in the femurs of C168-176 subline compared with the $\mathrm{B} 6$ control mice. There was no difference in body weight between C168-C176 and B6 control mice (Fig. 2), suggesting that the variation in BMD phenotype between congenic and B6 mice cannot be explained on the basis of size difference.

\section{Gene expression profiling}

In order to screen for potential BMD candidate genes in the $172-176 \mathrm{Mb}$ region, we compared the expression levels of all known genes and ESTs located in this region between the bones of the B6 control mice and the two congenic sublines described above. We chose gene expression change to identify candidate genes, since it is known that SNPs at both the regulatory regions (promoter, 3 '-UTR) and coding regions (via feedback loop) could affect the expression of the gene (Schadt et al. 2003; Chesler et al. 2005). In addition, this strategy has been successfully used in a recent study by Klein et al. (2004) to identify a QTL gene that negatively regulates peak bone density. Since C168-172 does not show a BMD phenotype it was used as a negative control, so only genes that showed a difference in the expression between C168-176 and B6, but not between C168-172 and B6, were further analyzed. Among all genes analyzed, only the Darc gene, located at $173.6 \mathrm{Mb}$, showed a sixfold increase of the expression in the C168-176 congenic subline when compared with the control progenitors (Supplemental Table 2), while no difference was found in expression between the C168-172 and B6 control mice. Since none of the other genes exhibited more than twofold difference that is significant, we focused on Darc as a candidate gene.

\section{Skeletal phenotype of Darc-KO mice}

If the increase of Darc gene expression in B6.CAST-1 congenic mice is responsible for the greater femur BMD exhibited by the C168-176 mice, we would expect Darc knockout (KO) mice to show a lower femur BMD compared with control mice. To test this hypothesis, we compared the phenotype of Darc-KO mice generated in a B6 background with that of age-gender-matched wild-type B6 progenitors. Body weight as well as femur length were similar for the two strains (Fig. 2), while total femur vBMD was increased in the Darc-KO mice compared with the wild-type control mice. The trabecular volume was $13 \%$ smaller in the Darc-KO mice compared with the wild-type mice $(P<0.01)$, the endosteal circumference was decreased by $3.8 \%$, and there was no change in periosteal circumference, which resembles the phenotype of the C168-176 subline and confirms the involvement of the Darc gene in BMD variation. Based on these data we considered an alternate possibility that the high expression of Darc might be secondary to a loss of the protein function.

\section{SNP analyses}

We next sequenced the Darc gene to determine the SNPs that might be the cause of the difference in the expression between 


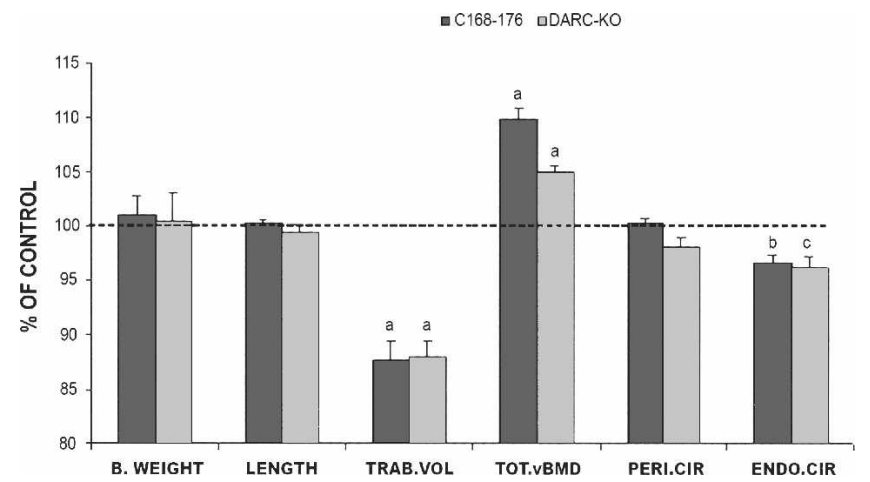

Figure 2. Femoral and body weight data from the $\mathrm{C} 168-176$ congenic subline of mice and Darc-KO mice. Data are expressed as a percentage of B6 and are mean \pm SEM. (a) $P<0.01$, (b) $P=0.01$, (c) $P=0.05$ as measured by Student's $t$-test, with $n=10-14$. (B.WEIGHT) Body weight, (LENGTH) femur length, (TRAB.VOL) total femur trabecular volume, (TOT.vBMD) total volumetric bone mineral density, (PERI.CIR) periosteal circumference, (ENDO.CIR) endosteal circumference.

the $\mathrm{B} 6$ mice and the high BMD congenic subline of mice. Using the NCBI database and in-house sequencing, we have identified 28 polymorphisms that distinguish the Darc gene in B6 from the CAST strain (Table 1), with three SNPs located at the promoter region, 15 polymorphism sequences located at the intervening sequence, and 10 polymorphisms at the coding region.

Table 1. Summary of sequence variants detected in Darc gene

\begin{tabular}{|c|c|c|c|c|}
\hline $\begin{array}{l}\text { Nucleotide change } \\
\text { CAST/C3H/B6 }\end{array}$ & $\begin{array}{l}\text { Polymorphism } \\
\text { position (bp) }\end{array}$ & Intron/exon & $\begin{array}{c}\text { Amino acid change } \\
\text { CAST/C } 3 \mathrm{H} / \mathrm{B} 6\end{array}$ & $\begin{array}{l}\text { Amino acid } \\
\text { position }\end{array}$ \\
\hline $\mathrm{A} / \mathrm{A} / \mathrm{C}$ & -456 & Promoter & & \\
\hline $\mathrm{A} / \mathrm{A} / \mathrm{C}$ & -325 & Promoter & & \\
\hline $\mathrm{G} / \mathrm{A} / \mathrm{G}$ & -234 & Promoter & & \\
\hline $\mathrm{T} / \mathrm{T} / \mathrm{G}$ & -169 & Promoter & & \\
\hline $\mathrm{A} /-/ \mathrm{T}^{\mathrm{a}}$ & 129 & Intron & & \\
\hline GT/GT/Del. & 131 & Intron & & \\
\hline $\mathrm{C} / \mathrm{C} / \mathrm{T}$ & 147 & Intron & & \\
\hline $\mathrm{C} / \mathrm{C} / \mathrm{T}$ & 163 & Intron & & \\
\hline $\mathrm{G} / \mathrm{A} / \mathrm{A}$ & 184 & Intron & & \\
\hline $\mathrm{T} / \mathrm{T} / \mathrm{C}$ & 201 & Intron & & \\
\hline $\mathrm{C} / \mathrm{C} / \mathrm{T}$ & 285 & Intron & & \\
\hline $\mathrm{T} / \mathrm{T} / \mathrm{C}$ & 308 & Intron & & \\
\hline $\mathrm{A} / \mathrm{A} / \mathrm{T}$ & 310 & Intron & & \\
\hline $\mathrm{A} / \mathrm{A} / \mathrm{G}$ & 372 & Intron & & \\
\hline $\mathrm{G} / \mathrm{G} / \mathrm{T}$ & 382 & Intron & & \\
\hline $\mathrm{A} / \mathrm{A} / \mathrm{T}$ & 405 & Intron & & \\
\hline $\mathrm{G} / \mathrm{G} / \mathrm{A}$ & 408 & Intron & & \\
\hline $\mathrm{T} / \mathrm{T} / \mathrm{C}$ & 454 & Intron & & \\
\hline $\mathrm{C} / \mathrm{C} / \mathrm{T}$ & 467 & Intron & & \\
\hline $\mathrm{C} / \mathrm{C} / \mathrm{A}$ & 493 & Exon 2 & $\mathrm{~T} / \mathrm{T} / \mathrm{N}$ & 10 \\
\hline $\mathrm{A} / \mathrm{A} / \mathrm{G}$ & 631 & Exon 2 & $D / D / G$ & 56 \\
\hline $\mathrm{G} / \mathrm{G} / \mathrm{T}$ & 644 & Exon 2 & $\mathrm{~L} / \mathrm{L} / \mathrm{L}$ & 60 \\
\hline $\mathrm{G} / \mathrm{A} / \mathrm{G}$ & 690 & Exon 2 & $\mathrm{G} / \mathrm{S} / \mathrm{G}$ & 76 \\
\hline $\mathrm{T} / \mathrm{C} / \mathrm{C}$ & 830 & Exon 2 & $\mathrm{H} / \mathrm{H} / \mathrm{H}$ & 122 \\
\hline $\mathrm{T} / \mathrm{T} / \mathrm{C}$ & 920 & Exon 2 & $\mathrm{~N} / \mathrm{N} / \mathrm{N}$ & 152 \\
\hline $\mathrm{T} / \mathrm{C} / \mathrm{T}$ & 997 & Exon 2 & $\mathrm{~L} / \mathrm{S} / \mathrm{L}$ & 178 \\
\hline $\mathrm{A} / \mathrm{A} / \mathrm{G}$ & 1044 & Exon 2 & $\mathrm{~T} / \mathrm{T} / \mathrm{A}$ & 194 \\
\hline $\mathrm{CT} / \mathrm{CT} / \mathrm{TG}$ & 1084 & Exon 2 & $\mathrm{~T} / \mathrm{T} / \mathrm{M}$ & 207 \\
\hline $\mathrm{T} / \mathrm{T} / \mathrm{C}$ & 1126 & Exon 2 & $\mathrm{~L} / \mathrm{L} / \mathrm{P}$ & 221 \\
\hline $\mathrm{C} / \mathrm{C} / \mathrm{T}$ & 1267 & Exon 2 & $\mathrm{~T} / \mathrm{T} / \mathrm{I}$ & 286 \\
\hline $\mathrm{T} / \mathrm{T} / \mathrm{C}$ & 1286 & Exon 2 & $\mathrm{C} / \mathrm{C} / \mathrm{C}$ & 292 \\
\hline
\end{tabular}

The positions of the SNPs in the promoter regions were taken according to the sequence reported by Luo et al. (2000), while the polymorphism sequences located within the gene from the start codon to the stop codon were taken according to CAST sequence AB039077. The gene was sequenced from $-580 \mathrm{bp}$ to the stop codon.

${ }^{\mathrm{a}}(-)$ Data unavailable.
Among the polymorphisms in the coding region, only six led to amino acid changes (Table 1). None of the polymorphisms discovered in the promoter region covered the consensus sequences that potentially regulate the transcription process, so it is likely that the difference in the expression of the Darc gene is due to the SNPs in the coding region. In order to determine if the SNPs in the Darc gene could be responsible for BMD variation, we compared the Darc gene sequence of B6 and CAST with another high BMD strain, namely $\mathrm{C} 3 \mathrm{H} / \mathrm{HeJ}(\mathrm{C} 3 \mathrm{H})$. We found that the six informative SNPs in the coding region were conserved in both CAST and $\mathrm{C} 3 \mathrm{H}$, suggesting that one or more of these SNPs could contribute to the high BMD phenotype exhibited by CAST and $\mathrm{C} 3 \mathrm{H}$ mice (Table 1).

\section{Binding assay}

The Darc gene is an acidic glycoprotein that spans the plasma membrane with seven transmembranous helices, like all members of the G-protein-coupled chemokine receptors (Fig. 3). As the name implies, the Darc protein is known to bind to several chemokines such as CC chemokines, monocyte chemotactic protein-1 (Ccl2), Ccl5 (regulated on activation, normal T cell expressed and secreted), and interleukin-8 (Il8). These cytokines have been shown to regulate formation and activity of osteoclasts via tumor necrosis factor ligand (Tnfsf11)-dependent and -independent mechanisms (Wise et al. 2002; Bendre et al. 2003, 2005; Kim et al. 2005).

Tournamille et al. (1997) have reported that the chemokine binding pocket of the Darc protein is located in the first and fourth extracellular domains, which are brought into close vicinity by a disulfide bridge (Fig. 3). Among the six SNPs found in the coding region, the aspartic acid at position 56 seems to be significant due to its location close to the cysteine at position 49 , which is required to form the disulfide bridge between transmembrane helices 1 and 7 in the chemokine binding pocket. The change of a small and neutral amino acid glycine with a negatively charged aspartic acid could change the conformation of the protein as well as the chemical environment of the binding sites, which consequently may affect the binding of the Darc protein to the chemokines and/or the stability of Darc protein. Accordingly, we predict that the Darc protein in CAST binds to chemokines much less efficiently compared with the Darc protein from B6 mice. The decreased protein function could contribute to increased expression as a consequence of loss of the feedback control. To test this hypothesis, we analyzed the binding of chemokines to nonadherent bone marrow cells (NABMC) derived from Darc knockout and congenic mice. We chose $\mathrm{Ccl} 2, \mathrm{Ccl} 5$, and Il8 as ligands for the binding studies based on previous findings that these chemokines bound to the Darc protein and all the three chemokines have been shown to regulate osteoclast formation. By using ${ }^{125}$ I-labeled $\mathrm{Ccl} 2$, Il8, and $\mathrm{Ccl} 5$ for the 


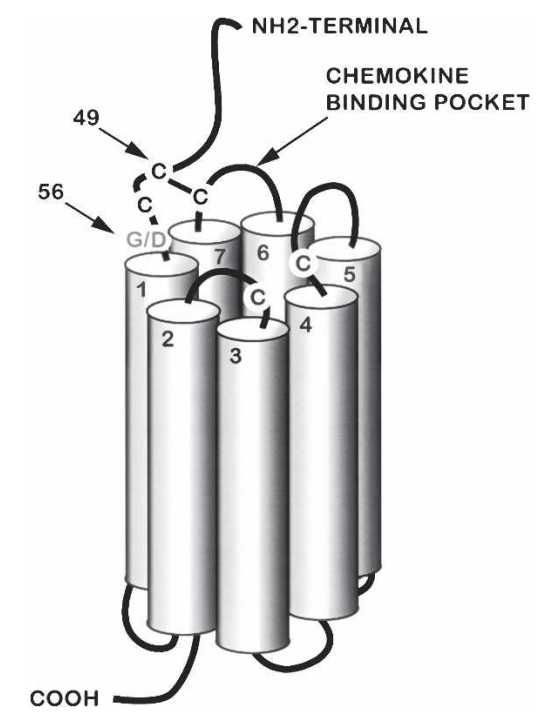

Figure 3. Schematic presentation of the predicted model of Darc protein based on analogy with the II8 type A receptor (modified from Tournamille et al. 1997). The three cysteine residues that form the chemokine binding site are brought into close proximity by a disulfide bridge between the first and the fourth extracellular domains of the Darc protein. The cysteine residue at the $\mathrm{N}$ terminus that forms the bridge is at position 49 in the mouse Darc sequence. The position of the SNP G56D is indicated.

binding studies, we found that the specific binding of the three chemokines was significantly reduced in the NABMC derived from both the C168-176 subline and Darc-KO mice compared with $\mathrm{B} 6$ mice (Fig. 4A).

\section{In vitro osteoclast formation assay}

Since Darc protein binds to a number of chemokines that regulate osteoclastogenesis, we next determined if reduced binding of chemokines to Darc in congenic mice is associated with corresponding changes in osteoclast formation.

We treated nonadherent bone marrow cells (NABMC) with Tnfsf11 and macrophage colony stimulating factor (Csf1), the two major cytokines reported to be involved in osteoclast formation (Quinn et al. 1998; Takahashi et al. 1999). The Darc-KO mice showed a $50 \%$ decrease in the number of TRAP-positive MNC compared with the wild-type mice. Furthermore, despite the increase of Darc gene expression in C168-176, this subline showed a 70\% decreased formation of TRAP-positive MNC compared with $\mathrm{B} 6$ control mice (Fig. 4B). In addition, treatment of NABMC with Darc-antibody (Darc-Ab) in the presence of Tnfsf11 and Csf1 resulted in a significant reduction in the number of TRAPpositive multinucleated cells (Fig. 4C,D). These data together offer strong evidence that Darc protein is involved in osteoclast formation and/or activity, and that the reduced osteoclast formation in the NABMC of CAST mice could be explained on the basis of reduced activity of Darc protein in CAST mice compared with $\mathrm{B} 6$ mice.

\section{In vivo histomorphometry study}

Consistent with the in vitro data, we found that the TRAPpositive bone resorbing surface was significantly reduced both at the endosteum $(47 \%, P=0.002)$ and the periosteum $(8 \%$, $P=0.02)$ of femurs isolated from Darc-KO mice compared with control mice as determined by histomorphometric analyses (Fig. 5). In contrast, bone formation rate was not significantly different in the femurs of Darc-KO mice compared with control mice (Fig. 5). We are in the process of breeding a congenic subline of mice carrying the Bmd1b locus for the purpose of performing histomorphometry studies in order to confirm that the increased $\mathrm{BMD}$ in congenic mice is also due to reduced bone resorption.

\section{Discussion}

Osteoporosis is a common disease characterized by reduced bone mass and increased risk of fragility fractures. Because of the well recognized importance of a genetic component in the pathogenesis of osteoporosis, there is now considerable interest among researchers in the bone field to identify genes that contribute to variation in peak bone mass. To identify osteoporosis genes, several approaches have been employed that include association studies and linkage analysis in humans and in experimental model organisms. While the association studies have identified a number of potential candidate genes that contribute to osteoporosis susceptibility, relatively few candidate gene polymorphisms have been validated by large-scale studies. Linkage studies in humans and various animal models, on the other hand, have revealed evidence in almost every chromosome for the presence of genetic loci that regulate bone mass (Beamer et al. 1999, 2001; Koller et al. 2000; Kammerer et al. 2003; Karasik et al. 2004; Volkman et al. 2004; Peacock et al. 2005; Ralston et al. 2005). Together, the association and linkage studies point to the fact that osteoporosis susceptibility is determined by a large number of genes with a modest or small effect size and not by few genes of major effect as originally thought. Accordingly, our data with a large number of congenic strains carrying overlapping CAST chromosomal segments from Chr 1 BMD QTL have revealed that there are at least four BMD loci in Chr 1, each contributing to $4 \%-12 \%$ of the variation in peak bone mass (this work and Edderkaoui et al. 2006).

The successful cloning of the QTL gene depends on the ability to resolve genetic effects into sufficiently small intervals to make gene identification feasible. In this regard, we were able to utilize strategies involving high-resolution mapping with a large number of markers and congenic sublines of B6 mice containing overlapping segments of CAST Chr 1 in the QTL region to successfully narrow down the size of the Bmd1b locus to $4 \mathrm{Mb}$. Since the $4-\mathrm{Mb}$ regions did not contain any obvious functional candidate gene for peak bone mass, we utilized the alternate approach of identifying candidate genes based on gene expression changes and SNP analyses. This approach led to the identification of the Darc gene, which was subsequently confirmed as a BMD QTL gene by functional studies. Our findings along with those of Klein et al. (2004) provide feasibility that the small effect of BMD QTL genes can be identified by an integrated approach involving fine mapping, use of congenic sublines containing the QTL gene, gene expression profiling, SNP analyses, and functional studies.

In the current study, Darc was identified as a BMD QTL1-2 candidate gene based on differential expression and SNP analyses between congenic sublines and B6 mice. The basis for the increased expression of Darc in congenic mice can only be speculated at this time. In this regard, it is possible that the loss of protein function caused by changes in key amino acids in the chemokine binding pocket could lead to increased expression due to the loss of negative feedback. Accordingly, we found re- 
A

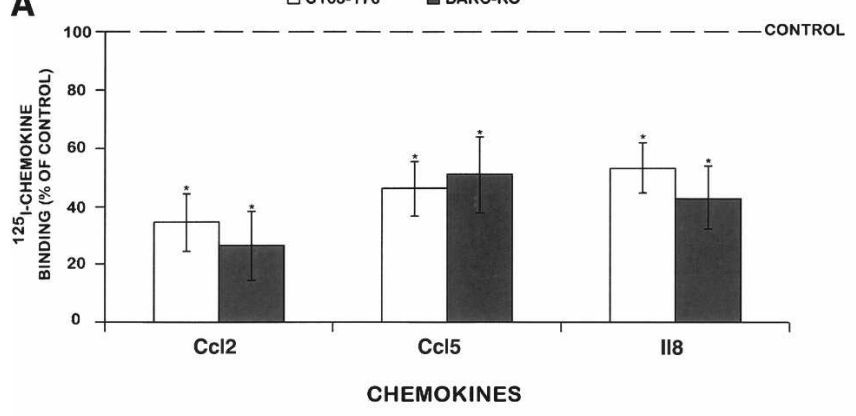

C
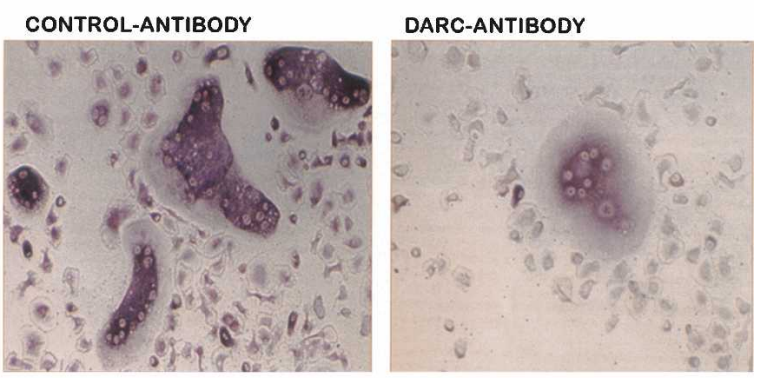
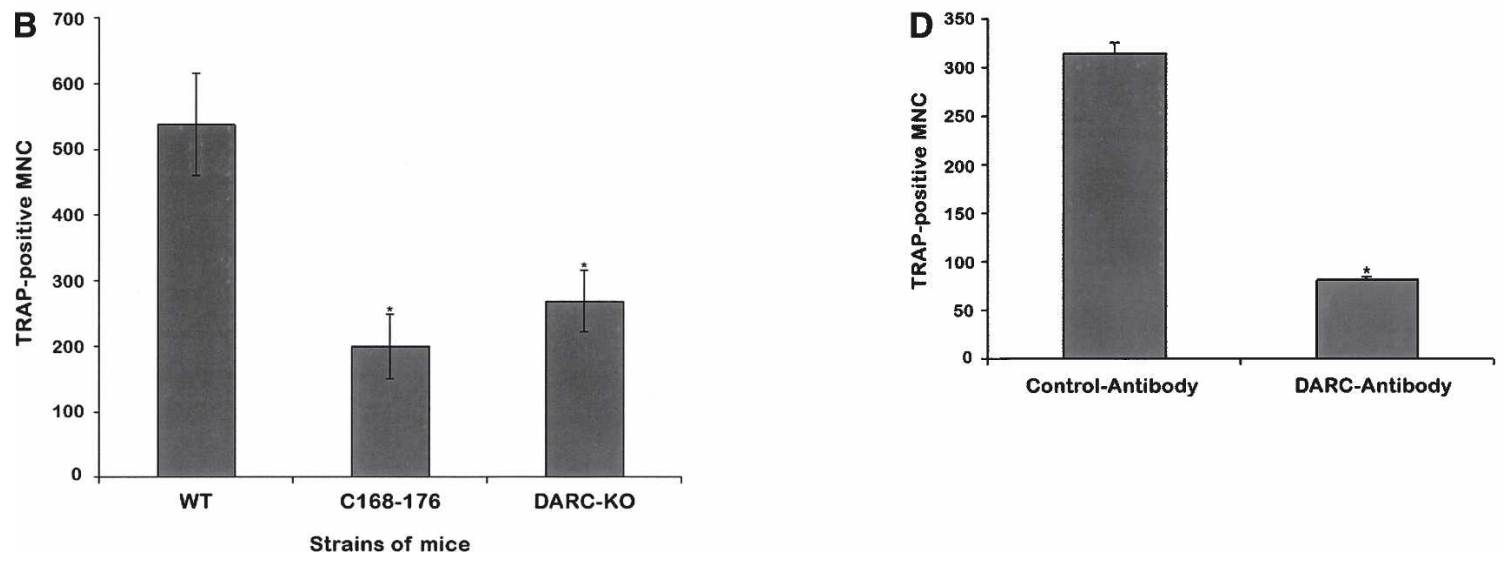

Figure 4. In vitro analysis of nonadherent bone marrow cells (NABMC) from B6, C168-176 congenic subline, Darc ${ }^{/+}$, and Darc ${ }^{-/-}$mice. $(A)$ Binding of three chemokines to NABMC. NABMC were incubated at $37^{\circ} \mathrm{C} / \mathrm{RT}$ in the presence of either ${ }^{125}$ I-chemokine only or both labeled and unlabeled chemokine. The specific binding was expressed as the CPM value in the absence of cold chemokine subtracted from the CPM value in the presence of cold chemokine. Data are expressed as a percentage of ${ }^{125}$ I-chemokine binding to NABMCs derived from B6 control mice, $n=8-10$. (B) Osteoclast generation in response to Tnfsf1 $1(100 \mathrm{ng} / \mathrm{mL})$ and Csf1 $(100 \mathrm{ng} / \mathrm{mL})$. After $10 \mathrm{~d}$ in culture, cells were stained for TRAP activity, and only cells with more than two nuclei (MNC: multinucleated cells) were counted. Data are expressed as a mean \pm SEM. Six to eight mice were used for each strain of mice. (WT) Wild-type mice. Groups were compared with wild-type mice with Student's $t$-test. $\left(^{*}\right) P<0.05$ vs. B6 control mice. (C) Effect of Darc-antibody on TRAP-positive cells derived from NABMC of wild-type B6 mice. After $6 \mathrm{~d}$ of treatment with goat polyclonal Darc-Ab in the presence of Tnfsf11 and Csf1 (right panel), the number of TRAP-positive multinucleated cells decreased considerably compared with cells treated with control IgG in presence of Tnfsf11 and Csf1 (left panel). (D) Number of TRAP-positive MNC derived from NABMC of wild-type B6 treated with Tnfsf11 and Csf1 in the presence of either Darc-antibody or control antibody. The data are expressed as mean \pm SEM. The experiment was repeated twice with cells derived from four mice each time. $\left(^{*}\right) P<0.05$ vs. control antibody (normal goat lgG).

duced binding of a number of chemokines to Darc from congenic mice compared with B6 mice. Alternatively, the increased expression may be caused by SNPs in the regulatory regions that are

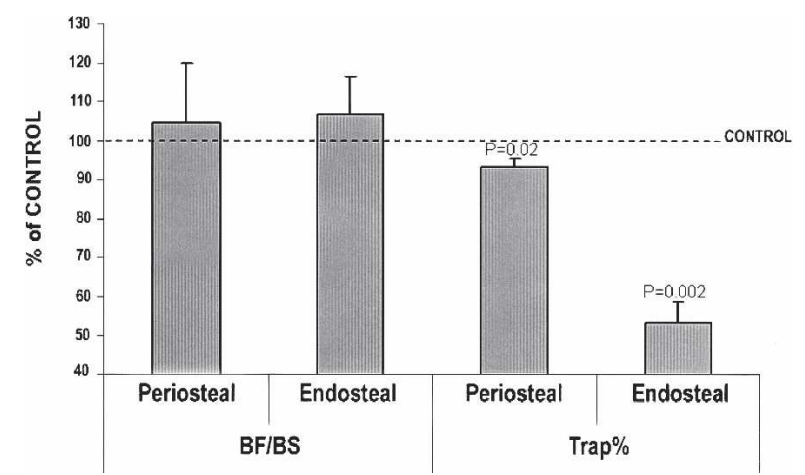

Figure 5. Bone formation and bone resorption rates in femur from Darc-KO mice. Bone formation is calculated as bone formation surface (BF) divided by total bone surface (BS). Bone resorption (Trap\%) is calculated as (the resorbing surface/bone surface) $\times 100$. The data are expressed as the percentage of wild-type values, $n=8-13,\left(^{*}\right) P<0.05$ vs. wild-type control mice. involved in transcriptional regulation and/or mRNA stability. In any case, the proof that the Darc gene is the BMD QTL1-2 gene came from in vitro and in vivo functional studies. We have found that Darc-knockout mice exhibited a similar skeletal phenotype as that of the congenic subline of mice carrying the Bmd1b locus. The higher BMD in the congenic subline of mice carrying the Bmd1b locus and Darc-knockout mice is contributed by cortical thickness that is caused by reduced endosteal circumference. The reduced bone marrow cavity in the absence of functional Darc could be due to reduced resorption and/or increased bone formation at the endosteum. In this regard, our in vitro osteoclast formation assay using NABMC revealed a significant reduction in osteoclast formation in NABMC derived from congenic as well as Darc-knockout mice compared with B6 mice. Consistent with these data, bone resorption but not bone formation was significantly reduced in the Darc-knockout mice compared with B6 mice. Based on these data, we conclude that Darc is a negative regulator of osteoclasts and that bone resorption is reduced in the absence of Darc, resulting in increased BMD.

As to how Darc regulates osteoclast formation, it is known that Darc binds to chemokines that are involved in osteoclast formation. Although Darc was first identified as Duffy blood 
antigen (Pogo and Chaudhuri 2000), there is now considerable evidence that Darc regulates cell trafficking and modulates the bioavailability of several chemokines such as $\mathrm{Ccl} 2$ and $\mathrm{Ccl} 5$ (Chaudhuri et al. 2003; Kashiwazaki et al. 2003), which are chemotactic signals for monocytes and are responsible for the migration of osteoclast precursors to fuse into differentiated osteoclasts (Kim et al. 2005). Therefore, based on our data and the previously published data about Darc and the chemokines function, we postulate a model of Darc involvement in osteoclast formation. As reported by Kim et al. (2005), the activation of osteoclast precursors by Tnfsf 11 and Csf 1 leads to an increase in the expression of $\mathrm{Ccl} 2$ and Ccl5, which are known to bind to Darc. Since Darc is involved in cell trafficking, and based on our finding that Darc-antibody inhibits osteoclast formation, we postulate that Darc-chemokine signaling is involved in osteoclast precursors trafficking for subsequent fusion into differentiated osteoclasts. Accordingly, the disruption of Duffy as in Darc-KO mice or C168-176 mice would lead to an alteration of osteoclast formation (Fig. 6). Our current studies are focused on testing the possibility that Darc is involved in the trafficking of osteoclast precursors for subsequent fusion.

In humans, the Duffy blood group system consists of four alleles, five phenotypes, and five antigens (Pogo and Chaudhuri 2000). Duffy-negative individuals are predominantly Africans and American blacks; they lack the Duffy protein on erythrocytes and are resistant to Plasmodium vivax and Plasmodium knowlesi infections (Miller et al. 1975, 1976). In addition, it has been well established that African-Americans exhibit significantly higher BMD compared with Caucasians (Yanovski et al. 2000; Cauley et al. 2005). Our finding that total femur vBMD is increased in Darc-KO mice compared with B6 mice raises the interesting possibility that BMD variation between African-Americans and Caucasians could be due in part to a difference in the function of Darc between the two groups.

Since Darc-KO mice were generated in a mixed genetic background involving 129 and B6 strains, it is important to rule out the possibility that another gene contributed by the 129 strain was responsible for the increased BMD in the Darc-KO mice. In this regard, Darc-KO mice used in this study have been backcrossed with B6 mice for at least eight generations to minimize the genetic contribution of the 129 strain. After eight backcrosses, the genetic contribution of the donor strain is estimated to be $<1 \%$ (Silver 1995). Accordingly, much of Chr 1 is derived

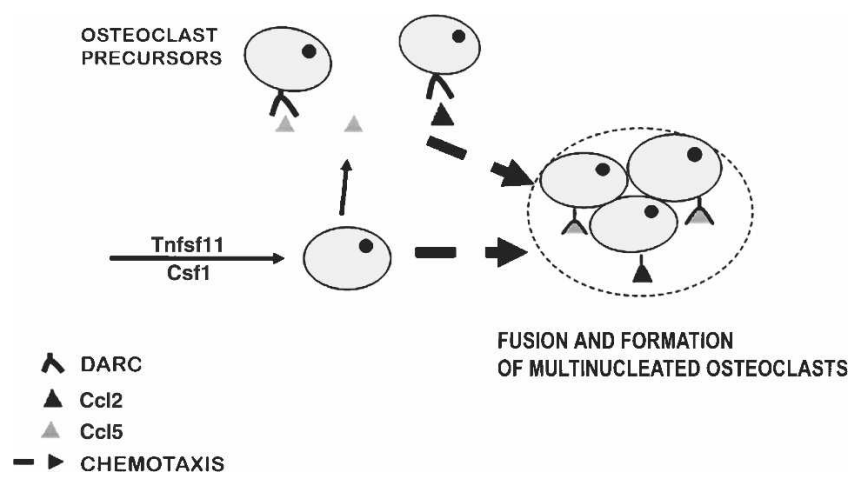

Figure 6. Model of Darc involvement in osteoclast generation. Activation of osteoclast precursors leads to increased expression of $\mathrm{Ccl} 2$ and $\mathrm{Ccl} 5$, which bind to Darc protein. Darc-chemokine signaling is involved in osteoclast precursor trafficking for subsequent fusion into differentiated osteoclasts. from B6 mice except a small region surrounding the Darc gene that was found to be homozygous for 129 (171-177 Mb), which was not surprising since homologous recombination to disrupt the Darc gene was carried out using stem cells derived from 129 mice, and since mice carrying the Darc-KO gene from 129 were selected for subsequent backcrosses with B6 mice. Our findings that NABMC derived from both congenic and Darc-KO mice exhibit reduced potential to form TRAP-positive multinucleated osteoclasts in vitro and that blockage of Darc action using neutralizing antibody to Darc reduced osteoclast formation in NABMC derived from B6 mice provided further experimental data for the Darc being the Chr 1 BMD QTL2 gene. However, the ultimate proof for Darc as a BMD QTL gene will require knock-in of a CAST copy of the Darc gene in the B6 background or vice versa and demonstration of the corresponding BMD phenotype in the knock-in mice.

In conclusion, this was the first study, to our knowledge, to provide strong evidence that the Darc gene plays an important role in regulating femur BMD via controlling osteoclastogenesis. Investigations into the molecular mechanism by which the Duffy protein regulates osteoclastogenesis could lead to the development of novel drug targets for the diagnosis and/or treatment of osteoporosis.

\section{Methods}

Mice

The study used two inbred strains of mice, C57BL/6J (B6) and CAST/EiJ (CAST), which have been previously shown to differ widely in total femur vBMD at 16 wk of age (Beamer et al. 1999). The rationale for selecting these two inbred mouse strains was based on the fact that these strains are highly polymorphic for genetic differences at $>95 \%$ of their genomes (Dietrich et al. 1996). The B6.CAST $F_{2}$ mice were produced and maintained at the animal research facility of The Jackson Laboratory (TJL; Bar Harbor, ME), as previously described (Beamer et al. 1999), while the congenic sublines of mice were generated and maintained at the Jerry L. Pettis VA Medical Center (LL; Loma Linda, CA) under the standard conditions previously described by Edderkaoui et al. (2006). The animal work performed in this study was approved by the institutional animal care and use committees at both TJL and LL. Darc-knockout (Darc-KO) mice as well as the control mice were generated as previously described by Luo et al. (2000), and were bred and maintained in LL under the same conditions previously described by Edderkaoui et al. (2006).

\section{Fine mapping the B6.CAST $\mathrm{F}_{2}$ population}

Spleens from 565 B6.CAST $\mathrm{F}_{2}$ female mice were received from Wes Beamer (TJL) to be used for genotyping. Extractions of genomic DNA from the spleens were performed following the Gentra PurGene protocol (PUREGENE Tissue kit, part no. D-7000A). In order to fine map the BMD QTL in Chr 1, we used 33 polymorphic markers located within the BMD QTL region that covers $24.6 \mathrm{cM}$ in mouse Chr 1, between D1mit106 and D1mit511 as described by Edderkaoui et al. (2006), instead of the seven markers that were previously used to identify the major BMD QTL in this region (Beamer et al. 1999). The number of markers was increased in order to detect and evaluate the effect of more potential recombinations within the major QTL region.

Genotyping data from the $\mathrm{F}_{2}$ population were analyzed using MapQTL (4.0) software (CPRO-DLO), and Mapmaker software was used to test the reproducibility of MapQTL data. MapQTL interval mapping was used for quantitative trait loci

\section{Genome Research}

www.genome.org 
mapping, and the LOD score significant thresholds were calculated using MapQTL permutation tests at a confidence level of $99 \%$.

\section{Generation of congenic sublines and genotyping}

The B6.CAST-1 ${ }^{\text {D1mit370-D1mit152 }}$ congenic (C168-185) subline, previously described by Edderkaoui et al. (2006), was used to generate more congenic sublines and break down the cast region first transferred to the $\mathrm{B} 6$ background. Additional crosses between the C168-185 congenic subline and the B6 progenitor produced new recombinations carrying smaller overlapping segments that were fixed by crossing the heterozygous mice of same recombination between one another. Each subline was genotyped using the polymorphic markers that encompass the region 168-185 Mb from the centromere (Edderkaoui et al. 2006).

Darc-KO mice were generated as previously described (Papaioannou and Johnson 1993; Luo et al. 2000) and backcrossed with C57BL mice. DNA extraction and genotyping were performed as described by Edderkaoui et al. (2006).

\section{Phenotypic analyses}

Based on data from previous studies, which showed that rapid acquisition of vBMD peaked at $\sim 16 \mathrm{wk}$, resulting in significant higher density values in the CAST females compared with the B6 females (Beamer et al. 1999), only females were used in this study and all measurements were performed at $16 \mathrm{wk}$ of age.

All the measurements for the B6.CAST $\mathrm{F}_{2}$ mice were performed at TJL as described by Beamer et al. (1999). For the B6 control mice and B6.CAST-1 congenic sublines of mice, bones were stored and processed as described by Edderkaoui et al. (2006).

The measured parameters for the congenic sublines of mice as well as knockout mice were expressed as the percentage of B6 control mice and were mean \pm SEM. Characteristics of the congenic sublines as well as knockout mice were compared with the B6 control progeny using a Student's $t$-test, and differences were judged statistically significant when $P<0.05$. Data from the congenic sublines mice were compared with $\mathrm{B} 6$ progenitors provided by TJL and bred in LL, while the Darc-KO mice data were compared with the B6 control mice provided by Dr. Chaudhuri (New York Blood Center, New York) and bred in LL.

\section{RNA isolation and real-time PCR analyses}

We isolated total RNA from femurs without bone marrow following the protocol supplied by Life Technologies Company using Trizol reagent. Since the BMD phenotype was analyzed in 16-wkold female mice, only female mice $14 \mathrm{wk}$ of age were used for gene expression studies to screen for candidate genes responsible for this phenotype. We synthesized cDNA by priming $500 \mathrm{ng}$ of total RNA with oligodT in the presence of M-MLV-reverse transcriptase following the manufacturer's protocol (http:// www.promega.com/tbs/9pim170/9pim170.pdf).

The quantification of mRNAs was performed in the ABI Prism 7900HT Sequence Detection System (Applied Biosystems) using SYBR Green as a detector dye. The reaction mixture contained $12.5 \mu \mathrm{L}$ of Brilliant SYBR Green (Stratagene), 2 pmol of each primer, $1 \mu \mathrm{L}$ of template cDNA, and RNase-free water to a final volume of $25 \mu \mathrm{L}$. The oligonucleotide primers were designated in order to amplify the most specific sequence in the coding region of each gene or EST. The relative differences in expression between the groups were determined using cycle time (Ct) values as follows: The $\mathrm{Ct}$ values of the genes of interest were first normalized with $18 \mathrm{~S}$ of the same sample; then the relative differences between the B 6 mice and congenic sublines of mice were calculated and expressed as relative increases or decreases, setting the control as $100 \%$. Assuming the Ct value reflects the initial starting copy and there is $100 \%$ efficiency, a difference of one cycle is equivalent to a twofold difference in starting copy.

If a significant difference in the expression between the congenic sublines and B6 mice was found for a certain gene, another pair of primers was used to confirm the results, so only the genes that showed a difference with at least two pairs of primers are reported herein. For the Darc gene, we have used four pairs of primers. The first two pairs of primers showed a 12-fold increase of the RNA expression in C168-176 compared with B6 mice. However, after sequence analysis, we found that the two primers used for real-time PCR (RT-PCR) covered the polymorphism sequences between B6 and CAST, so we decided to design new primers to determine whether the difference showed by RT-PCR was due to the mismatch or due to any difference in mRNA levels. The new primers that do not cover any SNP showed a sixfold increase of Darc expression in the C168-176 compared with B6 control mice.

The primers used to determine Darc gene expression level are:

Darc-F1. TCGGGTGGAAACCCTTTCA

Darc-R1. AGCTGGTGTCAGGCTGTAGTCA

Darc-F2. CCTGAATCCCAGACTGAATATTGG

Darc-R2. GAAAGGTGCAGAAGCCATTGTAA

Darc-F3. CCCATTCTGGCAGAGTTAGCA

Darc-R3. TCAACAGAGCTTGGGGAAAAA

Darc-F4. TTCTTCCACTGGCAGATTTGC

Darc-R4. ACCATACCCAGTAGCCCAGGTT

\section{SNPs analyses}

We identified SNPs by direct DNA sequence analysis of PCR products. To sequence the promoter region, we have designated primers using the DNA sequence reported by Luo et al. (2000). More primers were designated to amplify overlapping regions from the start codon to the stop codon of the Darc gene using a B6 sequence from NCBI, accession no. AC084073.

\section{Chemokine binding to nonadherent bone marrow cells}

Bone marrow cells were obtained from femurs isolated from 6-wk-old female B6, C168-176 subline, and Darc-KO mice. Femurs were dissected, the ends of the bones were cut, and the marrow was flushed out using a 2-mL syringe and transferred into $15-\mathrm{mL}$ Falcon tubes. Bone marrow cells were dispersed by repeated aspiration of the cell preparation containing Dulbecco's modified Eagle's medium (DMEM) supplemented with 10\% heatinactivated fetal bovine serum (FBS, HyClone). Cells were seeded in $10-\mathrm{cm}$ petri dishes and incubated at $37^{\circ} \mathrm{C}$ in a humidifier incubator with $5 \% \mathrm{CO}_{2}$. After $24 \mathrm{~h}$, all NABMC were transferred to new 50-mL Falcon tubes and were then counted with a hemocytometer. Cells were then spun down, the supernatant was removed, and the pellet was resuspended in binding medium (DMEM supplemented with $10 \mathrm{mM}$ HEPES, 0.1\% BSA at $\mathrm{pH}$ 7.4). Each reaction contained $2-4 \times 10^{6}$ cells in a total volume of 250 $\mu \mathrm{L}$ of binding buffer. Cells were incubated for $1 \mathrm{~h}$ at $37^{\circ} \mathrm{C}$ with 200,000 CPM ${ }^{125}$ I-MCP1 (Ccl2)/I18 and with or without unlabeled murine Ccl2/Human recombinant Il8 (PeproTech). We have found that $\mathrm{Ccl} 5$ binds better at room temperature (RT), so the cells were incubated with ${ }^{125}$ I-RANTES (Ccl5) for $3 \mathrm{~h}$ at RT with and without unlabeled murine RANTES (Ccl5). The reactions were terminated by centrifugation for $10 \mathrm{~min}$ at $3000 \mathrm{rpm}$. The supernatant was removed and the precipitates were washed three times with the binding buffer. Then the radioactivity was 
quantified using a gamma counter. Each reaction was carried out using 8-10 replicates.

\section{Cell culture}

NABMC were isolated as described above. The pellet was resuspended in DMEM supplemented with $10 \%$ FBS at a density of $8 \times 10^{5}$ cells $/ \mathrm{mL}$. Cells were then seeded into 24 -well plates at a density of $2 \times 10^{5}$ cells/well and treated with murine soluble Tnfsf11 (100 ng/mL, Peprotech) and murine colony-stimulating factor (Csf1, $100 \mathrm{ng} / \mathrm{mL}$, Peprotech). The cultures were maintained for up to $10 \mathrm{~d}$ and re-fed twice a week. After $10 \mathrm{~d}$ of treatment, the adherent osteoclasts were rinsed with phosphatebuffered saline (PBS), fixed with citrate (4\%)-acetone (60\%), and then stained using a Leukocyte acid phosphatase kit (SigmaAldrich). A Darc-specific polyclonal antibody (Darc-Ab) generated in a goat model against the N-terminal domain of the Darc mouse protein (Santa Cruz Biotechnology) was used to neutralize the Darc protein of B6 wild-type mice. NABMC were treated for $6 \mathrm{~d}$ with Tnfsf11 and Csf1 (as described above) in presence of Darc-Ab or control IgG (Sigma-Aldrich). Then the TRAP-positive (pink/purple) multinucleated (MNC) osteoclasts were visualized and counted under light microscopy, and only cells with more than two nuclei were considered.

\section{Histomorphometry study}

Femurs from 8-wk-old Darc-KO mice and wild-type B6 mice were defleshed and embedded in methylmethacrylate. Thick cross sections (0.5-mm thickness) were cut from the midpoint of the shaft with a diamond wire Histo-saw (Delaware Diamond Knives). The cross sections were ground lightly, mounted in aqueous Fluoromount-G (Fisher Scientific), and examined under an Olympus BH-2 fluorescent/brightfield microscope to measure bone areas and calcein labels. All bone histomorphometric parameters were measured as previously described (Kasukawa et al. 2003).

\section{Acknowledgments}

This work was supported by Assistance Award DAMD17-99-19571. The US Army Medical Research Acquisition Activity, 820 Chandler Street, Fort Detrick, MD 21702-5014, USA is the awarding and administering acquisition office. All work was performed in facilities provided by the Department of Veterans Affairs and the Jackson Laboratory (AR43618). The information contained in this publication does not necessarily reflect the position or the policy of the Government, and no official endorsement should be inferred. We thank Nancy R. Dunn, Nancy Lowen, and Joe Rung-Aroon for technical assistance.

\section{References}

Baldock, P.A. and Eisman, J.A. 2004. Genetic determinants of bone mass. Curr. Opin. Rheumatol. 16: 450-456.

Beamer, W.G., Donahue, L.R., Rosen, C.J., and Baylink, D.J. 1996. Genetic variability in adult bone density among inbred strains of mice. Bone 18: 397-403

Beamer, W.G., Shultz, K.L., Churchill, G.A., Frankel, W.N., and Baylink, D.J. 1999. Quantitative trait loci for bone density in C57BL/6J and CAST/EiJ inbred mice. Mamm. Genome 10: 1043-1049.

Beamer, W.G., Shultz, K.L., Donahue, L.R., Churchill, G.A., Sen, S., Wergedal, J.E., Baylink, D.J., and Rosen, C.J. 2001. Quantitative trait loci for femoral and lumbar vertebral bone mineral density in $\mathrm{C} 57 \mathrm{BL} / 6 \mathrm{~J}$ and $\mathrm{C} 3 \mathrm{H} / \mathrm{HeJ}$ inbred strains of mice. J. Bone Miner. Res. 16: $1195-1206$.

Bendre, M.S., Montague, D.C., Peery, T., Akel, N.S., Gaddy, D., and Suva, L.J. 2003. Interleukin-8 stimulation of osteoclastogenesis and bone resorption is a mechanism for the increased osteolysis of metastatic bone disease. Bone 33: 28-37.
Bendre, M.S., Margulies, A.G., Walser, B., Akel, N.S., Bhattacharrya, S., Skinner, R.A., Swain, F., Ramani, V., Mohammad, K.S., Wessner, L.L., et al. 2005. Tumor derived interleukin-8 stimulates osteolysis independent of the receptor activator of nuclear factor-кB ligand pathway. Cancer Res. 65: 11001-11009.

Cauley, J.A., Lui, L.Y., Ensrud, K.E., Zmuda, J.M., Stone, K.L., Hochberg, M.C., and Cummings, S.R. 2005. Bone mineral density and the risk of incident nonspinal fractures in black and white women. JAMA 293: $2102-2108$.

Chaudhuri, A., Rodriguez, M., Zbrzezna, V., Luo, H., Pogo, A.O., and Banerjee, D. 2003. Induction of Duffy gene (FY) in human endothelial cells and in mouse. Cytokine 21: 137-148.

Chesler, E.J., Lu, L., Shou, S., Qu, Y., Gu, J., Wang, J., Hsu, H.C., Mountz, J.D., Baldwin, N.E., Langston, M.A., et al. 2005. Complex trait analysis of gene expression uncovers polygenic and pleiotropic networks that modulate nervous system function. Nat. Genet. 37: 233-242.

Devoto, M., Shimoya, K., Caminis, J., Ott, J., Tenenhouse, A., Whyte, M.P., Sereda, L., Hall, S., Considine, E., and Williams, C.J. 1998. First-stage autosomal 27 genome screen in extended pedigrees suggests genes predisposing to low bone mineral density on chromosomes 1p, 2p and 4q. Eur. J. Hum. Genet. 6: 151-157.

Dietrich, W.F., Miller, J., Steen, R., Merchant, M.A., Damron-Boles, D., Husain, Z., Dredge, R., Daly, M.J., Ingalls, K.A., and O'Connor, T.J. 1996. A comprehensive genetic map of the mouse genome. Nature 380: 149-152.

Edderkaoui, B., Baylink, D.J., Beamer, W.G., Wergedal, J.E., Dunn, N.R., Shultz, K.L., and Mohan, S. 2006. Multiple genetic loci from CAST/EiJ chromosome 1 affect vBMD either positively or negatively in a C57BL/6J background. J. Bone Miner. Res. 21: 97-104.

Eisman, J.A. 1999. Genetics of osteoporosis. Endocr. Rev. 20: 788-804.

Kammerer, C.M., Schneider, J.L., Cole, S.A., Hixson, J.E., Samollow, P.B. O'Connell, J.R., Perez, R., Dyer, T.D., Almasy, L., Blangero, J., et al. 2003. Quantitative trait loci on chromosomes 2p, 4p, and 13q influence bone mineral density of the forearm and hip in Mexican Americans. J. Bone Miner. Res. 18: 2245-2252.

Karasik, D., Cupples, L.A., Hannan, M.T., and Kiel, D.P. 2004. Genome screen for a combined bone phenotype using principal component analysis: The Framingham study. Bone 34: 547-556.

Kashiwazaki, M., Tanaka, T., Kanda, H., Ebisuno, Y., Izawa, D., Fukuma, N., Akimitsu, N., Sekimizu, K., Monden, M., and Miyasaka, M. 2003. A high endothelial venule-expressing promiscuous chemokine receptor DARC can bind inflammatory, but not lymphoid, chemokines and is dispensable for lymphocyte homing under physiological conditions. Int. Immunol. 15: 1219-1227.

Kasukawa, Y., Baylink, D.J., Wergedal, J.E., Amaar, Y., Srivastava, A.K., Guo, R., and Mohan, S. 2003. Lack of insulin-like growth factor I exaggerates the effect of calcium deficiency on bone accretion in mice. Endocrinology 144: 4682-4689.

Kim, M.S., Day, C.J., and Morrison, N.A. 2005. MCP-1 is induced by receptor activator of nuclear factor- $\kappa \mathrm{B}$ ligand, promotes human osteoclast fusion, and rescues granulocyte macrophage colony-stimulating factor suppression of osteoclast formation. J. Biol. Chem. 280: 16163-16169.

Klein, R.F., Mitchell, S.R., Phillips, T.J., Belknap, J.K., and Orwoll, E.S. 1998. Quantitative trait loci affecting peak bone mineral density in mice. J. Bone Miner. Res. 13: 1648-1656.

Klein, R.F., Allard, J., Avnur, Z., Nikolcheva, T., Rotstein, D., Carlos, A.S., Shea, M., Waters, R.V., Belknap, J.K., Peltz, G., et al. 2004. Regulation of bone mass in mice by the lipoxygenase gene Alox15. Science 30: 229-232.

Koller, D.L., Econs, M.J., Morin, P.A., Christian, J.C., Hui, S.L., Parry, P., Curran, M.E., Rodriguez, L.A., Conneally, P.M., Joslyn, G., et al. 2000. Genome screen for QTLs contributing to normal variation in bone mineral density and osteoporosis. J. Clin. Endocrinol. Metab. 85: $3116-3120$.

Luo, H., Chaudhuri, A., Zbrzezna, V., He, Y., and Pogo, A.O. 2000. Deletion of the murine Duffy gene (Dfy) reveals that the Duffy receptor is functionally redundant. Mol. Cell. Biol. 20: 3097-3101.

Masinde, G.L., Li, X., Gu, W., Wergedal, J.E., Mohan, S., and Baylink, D.J. 2002. Quantitative trait loci for bone density in mice: The genes determining total skeletal density and femur density show little overlap in F2 mice. Calcif. Tissue Int. 71: 421-428.

Miller, L.H., Mason, S.J., Dvorak, J.A., McGinniss, M.H., and Rothman, I.K. 1975. Erythrocyte receptors for (Plasmodium knowlesi) malaria: Duffy blood group determinants. Science 189: 561-563.

Miller, L.H., Mason, S.J., Clyde, D.F., and McGinniss, M.H. 1976. The resistance factor to Plasmodium vivax in blacks. The Duffy-blood-group genotype, FyFy. N. Engl. J. Med. 295: 302-304.

Morrison, N.A., Qi, J.C., Tokita, A., Kelly, P.J., Crofts, L., Nguyen, T.V., Sambrook, P.N., and Eisman, J.A. 1994. Prediction of bone density 
Mouse Duffy is a BMD candidate gene in Chr 1

from vitamin D receptor alleles. Nature 367: 284-287.

Niu, T., Chen, C., Cordell, H., Yang, J., Wang, B., Wang, Z., Fang, Z., Schork, N.J., Rosen, C.J., and Xu, X. 1999. A genome-wide scan for loci linked to forearm bone mineral density. Hum. Genet. 104: $226-233$.

Papaioannou, V. and Johnson, R. 1993. Production of chimeras and genetically defined offspring from targeted ES cells. In Gene targeting, a practical approach (ed. A.L. Joyner), pp. 107-146. Oxford University Press, Oxford.

Peacock, M., Koller, D.L., Fishburn, T., Krishnan, S, Lai, D., Hui, S. Johnston, C.C., Foroud, T., and Econs, M.J. 2005. Sex-specific and non-sex-specific quantitative trait loci contribute to normal variation in bone mineral density in men. J. Clin. Endocrinol. Metab. 90: 3060-3066.

Pogo, A.O. and Chaudhuri, A. 2000. The Duffy protein: A malarial and chemokine receptor. Semin. Hematol. 37: 122-129.

Quinn, J.M., Elliott, J., Gillespie, M.T., and Martin, T.J. 1998. A combination of osteoclast differentiation factor and macrophage-colony stimulating factor is sufficient for both human and mouse osteoclast formation in vitro. Endocrinology 139: 4424-4427.

Ralston, S.H. 2002. Genetic control of susceptibility to osteoporosis. J. Clin. Endocrinol. Metab. 87: 2460-2466.

Ralston, S.H., Galwey, N., MacKay, I., Albagha, O.M., Cardon, L., Compston, J.E., Cooper, C., Duncan, E., Keen, R., Langdahl, B., et al. 2005. Loci for regulation of bone mineral density in men and women identified by genome wide linkage scan: The FAMOS study. Hum. Mol. Genet. 14: 943-951.

Schadt, E.E., Monks, S.A., Drake, T.A., Lusis, A.J., Che, N., Colinayo, V., Ruff, T.G., Milligan, S.B., Lamb, J.R., Cavet, G., et al. 2003. Genetics of gene expression surveyed in maize, mouse, and man. Nature 422: 297-302.

Silver, L.M. 1995. Mouse genetic concepts and applications. Oxford University Press. Adapted for the web (http://www.informatics.jax.org/silver/) by Mouse Genome Informatics. The Jackson Laboratory, Bar Harbor, ME, November 2001. Revised February 2005.

Takahashi, N., Udagawa, N., and Suda, T. 1999. A new member of tumor necrosis factor ligand family, ODF/OPGL/TRANCE/RANKL, regulates osteoclast differentiation and function. Biochem. Biophys. Res. Commun. 256: 449-455.

Tournamille, C., Le Van Kim, C., Gane, P., Blanchard, D., Proudfoot, A.E., Cartron, J.P., and Colin, Y. 1997. Close association of the first and fourth extracellular domains of the Duffy antigen/receptor for chemokines by a disulfide bond is required for ligand binding. $J$. Biol. Chem. 272: 16274-16280.

Volkman, S.K., Galecki, A.T., Burke, D.T., Miller, R.A., and Goldstein S.A. 2004. Quantitative trait loci that modulate femoral mechanical properties in a genetically heterogeneous mouse population. J. Bone Miner. Res. 19: 1497-1505.

Wise, G.E., Yao, S., Zhang, Q., and Ren, Y. 2002. Inhibition of osteoclastogenesis by the secretion of osteoprotegerin in vitro by rat dental follicle cells and its implications for tooth eruption. Arch. Oral Biol. 47: 247-254.

Yanovski, J.A., Sovik, K.N., Nguyen, T.T., and Sebring, N.G. 2000 Insulin-like growth factors and bone mineral density in African American and White girls. J. Pediatr. 137: 826-832.

Received October 3, 2006; accepted in revised form February 5, 2007. 


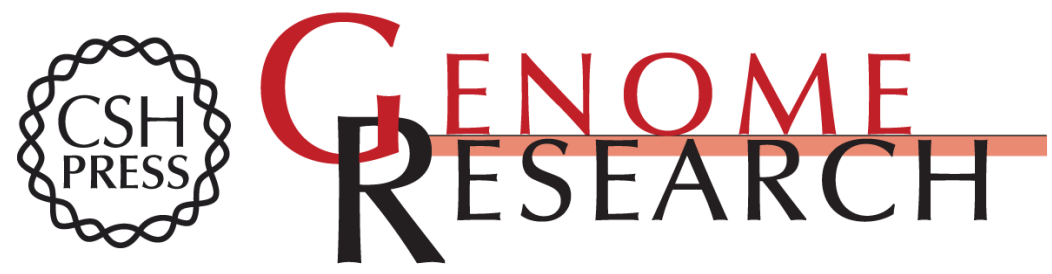

\section{Identification of mouse Duffy Antigen Receptor for Chemokines ( Darc) as a BMD QTL gene}

Bouchra Edderkaoui, David J. Baylink, Wesley G. Beamer, et al.

Genome Res. 2007 17: 577-585 originally published online April 6, 2007

Access the most recent version at doi:10.1101/gr.6009507

Supplemental Material

References

License

Email Alerting Service
http://genome.cshlp.org/content/suppl/2007/04/09/gr.6009507.DC1

This article cites 38 articles, 5 of which can be accessed free at: http://genome.cshlp.org/content/17/5/577.full.html\#ref-list-1

Receive free email alerts when new articles cite this article - sign up in the box at the top right corner of the article or click here.

\section{Affordable, Accurate Sequencing.}

